\title{
HUBUNGAN FISIKOKIMIA AIR TERHADAP KEANEKARAGAMAN UDANG AIR TAWAR DI PERAIRAN SUNGAI BEDERAK TERJUN KECAMATAN MEDAN MARELAN KOTA MADYA MEDAN
}

\author{
Laila Sapna, Meida Nugrahalia \\ Laboratorium Biologi Unimed, Jurusan Biologi, Program Studi Biologi, Universitas Negeri Medan \\ Jl. William Iskandar Psr V Medan Estate \\ Lailasapna27@gmail.com
}

\begin{abstract}
ABSTRAK
Penelitian ini bertujuan untuk mengetahui keadaan sifat fisikokimia perairan pada aliran Sungai Bederak, mengetahui keanekaragaman udang air tawar yang terdapat di aliran Sungai Bederak dan mengetahui hubungan fisikokimia air dengan keanekaragaman udang air tawar di aliran Sungai Bederak di Kelurahan Terjun, Kecamatan Medan Marelan. Pengukuran parameter fisika dilakukan langsung di lapangan, sedangkan pengukuran parameter kimia sampel air yang diamibil dari setiap stasiun diteliti di Laboratorium Badan Lingkungan Hidup Provinsi Sumatera Utara. Data hasil pengukuran suhu berkisar $24-28{ }^{\circ} \mathrm{C}$, kecerahan $3-7 \mathrm{~cm}, \mathrm{pH} 4,5-7,5$, COD $15-$ $19 \mathrm{mg} / \mathrm{L}, \mathrm{BOD} 12-13 \mathrm{mg} / \mathrm{L}$ dan $\mathrm{NO}_{3} 15-20 \mathrm{mg} / \mathrm{L}$. 1. Sifat fisikokimia perairan Sungai Bederak yakni suhu belum melewati batas baku mutu kelas II, sedangkan tingkat kecerahan sudah tercemar. Parameter kimia seperti $\mathrm{pH}$ sudah melewati batas baku mutu kelas II, COD belum melewati batas baku mutu kelas II, BOD sudah melewati batas baku mutu kelas II dan $\mathrm{NO}_{3}$ sudah melewati batas baku mutu kelas II. Pengambilan sampel udang dilakukan dengan menggunakan metode purposive sampling diambil dengan 3 kali pengulangan dan identifikasi udang diteliti di Laboratorium Biologi FMIPA UNIMED. Dari penelitian didapat 3 famili Crustacea yakni Palaemonidae, Tetrasquilidae, Penaeidae. Nilai indeks keanekaragaman udang $\left(\mathrm{H}^{\prime}\right)$ berkisar antara $0,65-1,86$. Hasil analisis korelasi menunjukan bahwa parameter fisika dan kimia yakni suhu 0,717, kecerahan 0,68, pH 0,65, COD 0,835, BOD 0,98, $\mathrm{NO}_{3}$ 0,86, memiliki hubungan terhadap keanekaragaman udang. Kontribusi hubungan suhu 51,4 \%, kecerahan 46,2 \%, pH 42,2 $\%$, COD $69,7 \%$, BOD $96 \%, \mathrm{NO}_{3} 73,9 \%$.
\end{abstract}

Kata kunci : Fisikokimia, Udang, Keanekaragaman, Analisis Korelasi

\section{THE CORRELATION BETWEEN PHYSICOCHEMICAL WATER CONDITION AND THE DIVERSITY OF FRESH WATER PRAWNS IN BEDERAK TERJUN RIVER ON MEDAN MARELAN DISTRICT OF MEDAN CITY}

\begin{abstract}
This study aims to know the condition of water physicochemistry of Bederak River, to know the diversity of shrimp in Bederak River and to know the correlation between water physicochemical with shrimp diversity in Bederak River in Terjun, Marelan District. The physical parameter measurement was done directly in the field, while the measurement of chemical parameters of water sample which taken from each station was done in the Laboratory of Environment Agency, North Sumatera. The data were obtained from the temperature measurements ranged from $24-28{ }^{\circ} \mathrm{C}$, the brightness ranged from 3 to $7 \mathrm{~cm}$, the $\mathrm{pH}$ ranged from 4.5 to 7.5, the COD ranged from 15 to $19 \mathrm{mg} / \mathrm{L}$, BOD ranged from 12 to $13 \mathrm{mg} / \mathrm{L}$ and NO3 ranged $15-20 \mathrm{mg} / \mathrm{L}$. The condition of physicochemical properties in Bederak River waters on physical parameters such as temperature has not exceeded the standard quality limit of class II, while the brightness level has been contaminated and according to chemical parameters such as $\mathrm{pH}$ has exceeded the standard quality limit of class II, COD has not passed the standard quality limit of class II, BOD Beyond the limit of class II and $\mathrm{NO}_{3}$ quality standards have exceeded the
\end{abstract}


limit of class II quality standards set by the government. Shrimp sampling was done by purposive sampling method that was taken with 3 times of repetition and the shrimp was identified in Biology Laboratory of FMIPA UNIMED. As the result, there are 3 families of Crustacea, those are: Palaemonidae, Tetrasquilidae, and Penaeidae. The value of shrimp diversity index ( $\left.\mathrm{H}^{\prime}\right)$ ranged from 0.65 to 1.86 . The result of correlation analysis shows that the physical and chemical parameters are temperature 0,717, brightness 0,68, pH 0,65, COD 0,835, BOD 0,98, $\mathrm{NO}_{3} 0.86$ are relates to the diversity of shrimp. The contribution of each relation temperature $51.4 \%$, brightness $46.2 \%$, $\mathrm{pH} 42.2 \%$, COD 69.7\%, BOD 96\%, $\mathrm{NO}_{3} 73.9 \%$.

Keyword: Physicochemical, Shrimp, Diversity, Correlation Analysis

\section{Pendahuluan}

Pencemaran sungai merupakan masalah yang membuat sumber air tidak dapat digunakan sebagaimana mestinya. Salah satu daerah aliran sungai (DAS) di Indonesia yaitu DAS Bederak mempunyai masalah banjir dan penurunan kualitas air. Penurunan kualitas air diduga disebabkan oleh banyaknya permukiman dan industri yang tumbuh di DAS Bederak.

Pembuangan limbah pabrik atau industri, pertanian, maupun limbah domestik dari suatu pemukiman penduduk ke dalam badan air dapat menyebabkan terjadinya degradasi kualitas air, karena adanya pencemaran yang dapat mempengaruhi sifat kimia, fisika, dan biologi perairan. Suatu perairan memiliki satu kesatuan antara komponen fisika, kimia, dan biologi dalam suatu media air. Apabila salah satu dari ketiga sifat air tersebut mengalami perubahan maka akan berpengaruh terhadap sifat-sifat air yang lainnya. Perubahan kualitas air yang terjadi berpotensi mengganggu komunitas perairan khususnya hewan akuatik, karena hewan akuatik akan merasakan dampaknya secara langsung (Kanwilyanti, dkk, 2013).

Pada keadaan normal, faktor fisikokimia air sangat berpengaruh dalam kehidupan hewan akuatik. Hewan memiliki toleransi dan batas maksimum nilai parameter mutu air bagi kehidupan (Parlaungan, 2015). Sebagai contoh suhu berpengaruh langsung pada metabolisme udang. Pada suhu tinggi metabolisme udang dipacu, sedangkan pada suhu yang lebih rendah proses metabolisme diperlambat (Kanwilyanti, dkk, 2013). menurut Suparjo, (2008), kisaran pH yang baik untuk kehidupan dan pertumbuhan ikan ataupun udang adalah antara 7 - 8,5.
Sungai Bederak merupakan sungai yang bernilai ekonomi, karena sebagian mata pencarian masyarakat di Kelurahan Terjun Kecamatan Medan Marelan adalah nelayan. Hasil Tangkapan nelayan seperti udang air tawar dan ikan yang terdapat di Sungai Bederak menjadi sumber pencarian utama sebagian besar masyarakat sekitar Sungai Bederak. Sehingga udang pada Sungai Bederak perlu dilesetarikan agar perekonomian masyarakat sekita tidak hilang.

Sebagai bagian dari ekosistem air tawar, udang air tawar juga berperanan dalam menjaga keseimbangan ekosistem. Salah satunya sebagai komponen mata rantai makanan. Udang berperan sebagai pakan bagi hewan akuatik yang lebih besar dalam mata rantai makanan. Selain itu udang juga berperan sebagai pemakan bangkai dan detritus di perairan. Pelestarian udang air tawar menjadi penting dilakukan agar keseimbangan ekosistem dapat dipertahankan (Rahmi, dkk, 2016).

\section{Bahan dan Metode}

Penelitian identifikasi udang dilaksanakan di Laboratorium Biologi Universitas Negeri Medan, Sumatera Utara. Pengambilan data Penelitian dilaksanakan pada bulan Maret 2017 di perairan Sungai Bederak Tejun. Pengambila sampel udang dilakukan pada lima stasiun dengan tiga kali pengulangan yaitu pagi (07.00 WIB), siang (13.00 WIB), dan sore (17.00 WIB). Udang yang didapat diidentifikasi berdasarkan buku identifikasi dan diolah menggunakan rumus keanekaragaman Shannon - Wienner, untuk melihat hubungan antara pencemaran air dengan keanekaragaman udang digunakan rumus korelasi. 


\section{Hasil Dan Pembahasan \\ Hasil}

1. Kondisi Fisikokimia Perairan Sungai Berderak

Tabel 1.1. Data Hasil Pengukuran Parameter Fisikokimia Perairan Sungai Bederak

\begin{tabular}{|c|c|c|c|c|c|c|c|}
\hline No & \multirow{2}{*}{$\begin{array}{c}\text { Parameter } \\
\text { fisikokimia }\end{array}$} & \multicolumn{5}{|c|}{ Stasiun } & Rata \\
\cline { 3 - 7 } & & & 2 & 3 & 4 & 5 & $\begin{array}{c}- \\
\text { rata }\end{array}$ \\
\hline 1. & Suhu & 24 & 24 & 25 & 27 & 28 & 25,6 \\
\hline 2. & $\begin{array}{c}\text { Penetrasi } \\
\text { cahaya }\end{array}$ & 3 & 4 & 6 & 6 & 7 & 5,2 \\
\hline 3. & Ph & 4,5 & 5,1 & 7,3 & 7,2 & 7,5 & 6,84 \\
\hline 4. & COD & 16 & 15 & 18 & 17 & 19 & 17 \\
\hline 5. & BOD & 12,5 & 12 & 12,5 & 13 & 13 & 12,6 \\
\hline 6. & $\mathrm{NO}_{3}$ & 15 & 16 & 19 & 17 & 20 & 17,4 \\
\hline
\end{tabular}

Hasil pengukuran parameter fisika dan kimia pada pengamatan yang dilakukan didapat hasil rata - rata dari suhu 25,6, kecerahan 5,2, pH 6,8, COD 17,0, BOD 12,6 dan $\mathrm{NO}_{3} 17,4$.

\section{Indeks Keanekaragaman Udang}

Tabel 1.2. Nilai keanekaragaman ( $\left.\mathrm{H}^{\prime}\right)$ udang pada masing - masing stasiun penelitian.

\begin{tabular}{|c|c|c|c|c|c|}
\hline \multirow{2}{*}{$\begin{array}{c}\text { Indeks } \\
\text { keanekaragaman }\end{array}$} & \multicolumn{5}{|c|}{ Stasiun } \\
\cline { 2 - 6 } & I & II & III & IV & V \\
\cline { 2 - 6 } & 0,65 & 1,08 & 0,91 & 1,59 & 1,86 \\
\hline
\end{tabular}

Pada tabel 1.2. dapat terlihat bahwa nilai keanekaragaman $\left(\mathrm{H}^{\prime}\right)$ udang yang di dapat pada kelima stasiun penelitian berkisar antara $0,65-1,86$. Indeks keanekaragaman terendah terdapat pada stasiun I yaitu 0,65 . Sedangkan Indeks keanekaragaman $\left(\mathrm{H}^{\prime}\right)$ tertinggi terdapat pada stasiun $\mathrm{V}$ yaitu 1,86 yang merupakan stasiun kontrol yang tidak ada lagi aktivitas masyarakat dan industri rumah tangga. Dari hasil tangkapan udang didapat 3 jenis famili dari 8 jenis udang yang didapat diantaranya familiy Palaemonidae, Tetrasquillidae dan Penaidae.

\section{Kondisi Fisikokimia Peraian Sungai Bederak}

Tingkat pencemaran air dapat ditentukan melalui tiga parameter yaitu parameter fisika, kimia dan biologi. Menurut parameter fisika dan kimia perairan Sungai Bederak beberapa parameter sudah melewati batas baku mutu kelas II pada Peraturan Pemeintah Nomor 82 tahun 2001.

Nilai suhu pada baku mutu kelas II Peraturan Pemeintah Nomor 82 tahun 2001 yaitu $23^{\circ} \mathrm{C}-28^{\circ} \mathrm{C}$, sedangkan suhu yang didapat pada stasiun I $24^{\circ} \mathrm{C}$, stasiun II $24^{\circ} \mathrm{C}$, stasiun III $25^{\circ} \mathrm{C}$, stasiun IV $27^{\circ} \mathrm{C}$ dan stasiun V $28^{\circ} \mathrm{C}$ berarti suhu yang didapat dari stasiun I sampai dengan stasiun $\mathrm{V}$ belum melewati batas baku mutu yang sudah ditentukan pemerintahan.

Nilai kecerahan pada baku mutu kelas II Peraturan Pemerintah Nomor 82 tahun 2001 tidak ada ditentukan, sedangkan kecerahan yang didapat pada stasiun I $3 \mathrm{~cm}$, stasiun II 4 $\mathrm{cm}$, stasiun III $6 \mathrm{~cm}$, stasiun IV $6 \mathrm{~cm}$ dan stasiun V $7 \mathrm{~cm}$ berarti nilai kekeruhan yang didapat pada stasiun I dan Stasiun II tingkat kecerahan pada stasiun ini sangat kecil terlihat dari warna air pada stasiun ini keruh dan banyak sampah yang berada disekitar perairan karena pada stasiun ini terdapat pabrik tahu, pabrik pembuatan gula aren dan peternakan kambing yang limbahnya dibuang langsung ke perairan Sungai Bederak sehingga warna air pada stasiun ini lebih keruh.

Berdasarkan acuan pada parameter kimia nilai $\mathrm{pH}$ pada baku mutu kelas II Peraturan Pemerintah Nomor 82 tahun 2001 yaitu $6-9$, sedangkan $\mathrm{pH}$ yang didapat pada stasiun I 4,5, stasiun II 5,1, stasiun III 7,3, stasiun IV 7,2 dan stasiun $\mathrm{V}$ 7,5 berarti $\mathrm{pH}$ yang didapat dari stasiun I dan stasiun II sudah melewati batas baku mutu yang sudah ditentukan pemerintahan, menurut Suyanto, dkk, (1989) kisaran normal $\mathrm{pH}$ air untuk udang berkisar antara 7,5 - 8,5, tetapi pada $\mathrm{pH}$ 6,4 dapat menurunkan laju pertumbuhan sebesar $60 \%$, sebaliknya pada $\mathrm{pH}$ tinggi 9 9,5 dapat menyebabkan peningkatan kadar amoniak sehingga secara tidak langsung dapat membahayakan udang.

Nilai COD pada baku mutu kelas II Peraturan Pemerintah Nomor 82 tahun 2001 yaitu $25 \mathrm{mg} / \mathrm{L}$, sedangkan nilai COD yang didapat pada saat penelitian pada stasiun I 16 $\mathrm{mg} / \mathrm{L}$, stasiun II $15 \mathrm{mg} / \mathrm{L}$, stasiun III $18 \mathrm{mg} / \mathrm{L}$, stasiun IV $17 \mathrm{mg} / \mathrm{L}$ dan stasiun V $19 \mathrm{mg} / \mathrm{L}$ berarti nilai COD yang didapat dari stasiun I 
sampai stasiun $\mathrm{V}$ belum melewati batas baku mutu yang sudah ditentukan pemerintahan.

Nilai BOD pada baku mutu kelas II Peraturan Pemerintah Nomor 82 tahun 2001 yaitu $3 \mathrm{mg} / \mathrm{L}$, sedangkan nilai BOD yang didapat pada stasiun I $12,5 \mathrm{mg} / \mathrm{L}$, stasiun II $12 \mathrm{mg} / \mathrm{L}$, stasiun III 12,5 mg/L, stasiun IV 13 $\mathrm{mg} / \mathrm{L}$ dan stasiun V $13 \mathrm{mg} / \mathrm{L}$ berarti nilai BOD yang didapat dari stasiun I sampai stasiun $\mathrm{V}$ sudah melewati batas baku mutu yang ditentukan pemerintahan. Penguraian zat organik adalah peristiwa alamiah kalau sesuatu badan air dicemari oleh zat organik, bakteri dapat menghabiskan oksigen terlarut, dalam air selama proses oksidasi tersebut yang bisa mengakibatkan kematian ikan-ikan dan udang dalam air dan keadaan menjadi anaerobik dan dapat menimbulkan bau busuk pada air.

Nilai $\mathrm{NO}_{3}$ pada baku mutu kelas II Peraturan Pemerintah Nomor 82 tahun 2001 yaitu $10 \mathrm{mg} / \mathrm{L}$, sedangkan nilai $\mathrm{NO}_{3}$ yang didapat pada saat penelitian pada stasiun I 15 $\mathrm{mg} / \mathrm{L}$, stasiun II $16 \mathrm{mg} / \mathrm{L}$, stasiun III $19 \mathrm{mg} / \mathrm{L}$, stasiun IV $17 \mathrm{mg} / \mathrm{L}$ dan stasiun V $20 \mathrm{mg} / \mathrm{L}$ berarti nilai $\mathrm{NO}_{3}$ yang didapat dari stasiun I sampai stasiun $\mathrm{V}$ belum melewati batas baku mutu yang ditentukan pemerintah. Menurut Steven (2011) Kandungan nitrat di perairan sangat penting dalam menunjang keutuhan ekosistem perairan. Hal itu terjadi karena nitrat merupakan unsur yang digunakan dalam proses fotosintesis dan merupakan unsur yang digunakan untuk pertumbuhan organisme akuatik. Kadar nitrat yang banyak dalam suatu perairan dapat dikatakan bagus atau subur karena dengan nitrat maka organisme akuatik akan banyak disuatu perairan sehingga akan terjadi proses fotosintesis dimana menghasilkan $\mathrm{O}_{2}$ yang sangat dibutuhkan bagi organisme akuatik.

\section{Indeks Keanekaragaman Udang}

Keanekaragaman udang dalam suatu perairan menunjukkan kondisi lingkungan perairan terhadap kelangsungan hidup suatu populasi jenis udang tersebut. Menurut Supriharyono (2000), sifat fisik-kimia perairan yang khas menunjukkan kondisi lingkungan yang bervariasi sehingga menyebabkan organisma yang hidup di perairan tersebut memiliki kekhasan pula.
Naamin, et al (1981) mengatakan udang Penaeid paling banyak ditemukan di sepanjang pantai pada substrat dasar perairan yang berlumpur dan berpasir serta didukung oleh keberadaan hutan mangrove, terutama di daerah yang masih dipengaruhi oleh muara sungai sampai kedalaman 30-40 meter.

Nybakken (1992) mengatakan bahwa perairan muara miskin akan flora karena semua bagian dasar yang terdiri dari substrat berlumpur tidak cocok untuk melekatnya makroalga sehingga lapisan bawah perairan ini sering kali tanpa tumbuhan yang hidup dan di perairan ini berbagai macam udang hanya hidup pada fase juvenile sedang yang dewasa terdapat di laut. Seperti diketahui perairan dengan tumbuhan yang cukup merupakan tempat paling ideal bagi kehidupan udang.

Dari hasil tangkapan udang didapat 3 jenis famili dari 8 jenis udang yang didapat diantaranya familiy Palaemonidae, Tetrasquillidae dan Penaidae. Dari 3 family tersebut family Penaidae yang sering di jumpai pada setiap stasiun penelitian. Family Palaemonidae hanya ditemukan 2 jenis udang, sedangkan family Tetrasquillidae hanya ditemukan 1 satu jenis udang.

Adapun deskripsi jenis udang yang didapat di perairan Sungai Bederak Terjun Kecamatan Medan Marelan Kota Madya Medan adalah sebagai berikut :

1. Famili Udang Palaemonidae

Menurut (Motoh, 1980) deskrpsi udang famili udang Palaemonidae carapace dan Perut halus Rostrum hampir lurus dengan keel yang menonjol pada sisinya, ujungnya meluas sedikit di luar yang pertaman antennal peduncle, dan dipersenjatai dengan enam sampai delapan dorsal dan dua ke tiga gigi ventral. Pasangan kedua kaki berjalan memiliki banyak tuberkel kecil berkembang dengan baik pada udang jantan dan betina. Capit yang bergerak dan tak tergoyahkan melengkung di ujungnya, panjangnya 1 dan $1 / 2$ kali panjang tubuh total. Capit berwarna coklat keabu-abuan dengan bercak kuning keputihan yang tidak beraturan. 


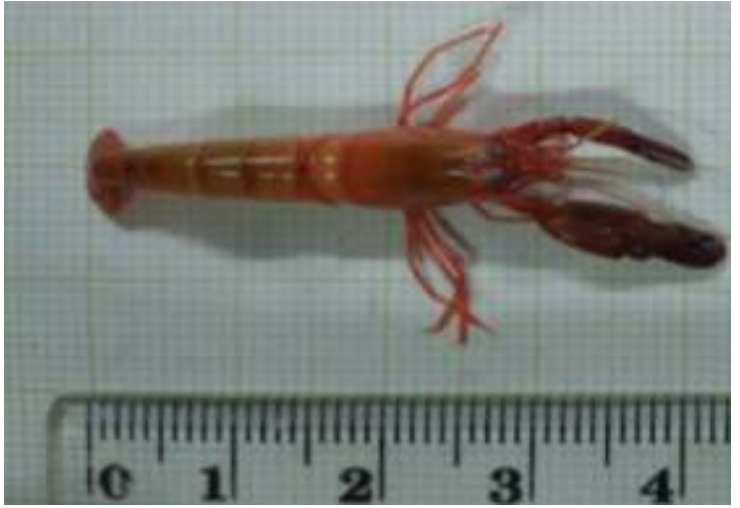

Gambar 1.1. Gambar Famili Udang Palaemonidae

2. Famili Udang Tetrasquillidae

Menurut (Davie, 2002) deskrpsi udang famili Tetrasquillidae memiliki lapisan mata yang biasanya dengan enam baris mata majemuk yang berbentuk heksagonal dibagian kepala. Maxilliped ketiga dan keempat dengan propodi berusuk atau manik-manik dibagian ventral.abdominal artikulasi kompak. Capit dengan dactylus pada dasarnya. dilengkapi dengan 3 pasang kaki berjalan (peripoda) endopoda oval memanjang. Telson dengan gigi primer dan dentikula kulit berbeda, ramping, tidak menyatu. Duri punggung yang membentuk kipas dengan lipatan proksimal dorsal.

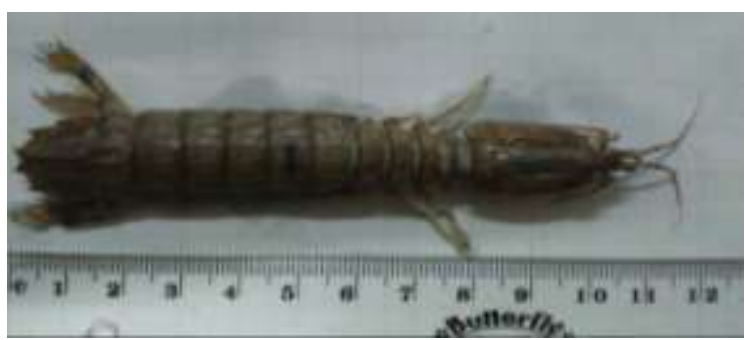

Gambar 1.2. Gambar Famili Udang Tetrasquillidae

3. Famili Udang Penaeidae

Menurut (Motoh, 1980) deskrpsi udang famili udang penaeidae adalah udang di perairan Asia Tenggara yang merupakan salah satu tangkapan terbesar yang ada. Tubuh sangat licin, karapas dengan perkembangan yang baik, duri anterior dan hati carina lurus. Rostrum biasanya dipersenjatai Tujuh atau delapan dorsal dan tiga gigi ventral. Warna tubuh kemerahan dengan lebih gelap dan

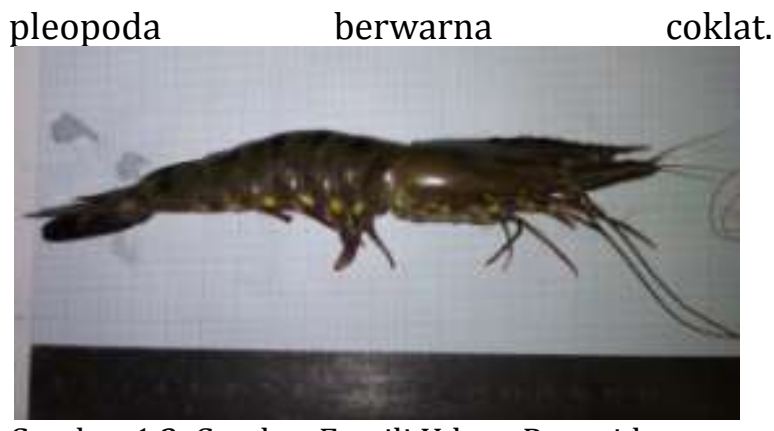

Gambar 1.3. Gambar Famili Udang Penaeidae

\section{Hubungan Fisikokimia Air Terhadap Keanekaragaman Udang \\ Untuk mengetahui hubungan} pencemaran air dengan keanekaragaman udang dalam penelitian ini menggunakan analisis korelasi. Parameter fisika dan kimia yang diperhitungkan diantaranya Suhu, kecerahan, $\mathrm{pH}, \mathrm{COD}$ dan $\mathrm{BOD}, \mathrm{NO}_{3}$. Sedangkan nilai keanekaragaman didapat dari hasil perhitungan indeks keanekaragaman.

a. Suhu

Analisis korelasi suhu dengan keanekaragaman udang menunjukan hasil koefisien korelasi 0,717 . Hal ini berarti adanya hubungan yang kuat antara keduanya. Nilai koefisien determinasi yang diperoleh 51,4\%. Artinya besarnya kontribusi suhu terhadap keanekaragaman udang sebesar 51,4\%. Perbedaan suhu air pada tiap pengukuran disebabkan perbedaan intensitas cahaya yang mengenai air, maupun akibat penutupan permukaan air pada masing-masing stasiun. Pada stasiun I sampai IV tampak bahwa vegetasi lebih sedikit dan banyaknya aktivitas industri yang terjadi, namun kondisi sebaliknya ditemukan pada stasiun V.

b. Kecerahan

Analisis korelasi kekeruhan dengan keanekaragaman udang menunjukan hasil koefisien korelasi 0,68. Hal ini berarti adanya hubungan yang sedang atau cukup antara keduanya. Nilai koefisien determinasi yang diperoleh 46,2 \%. Artinya besarnya kontribusi kecerahan terhadap keanekaragaman udang sebesar 46,2 \%. Nilai kecerahan terendah pada stasiun I kawasan ini merupakan kawasan yang dekat dengan perumahan dan industri tahu, oleh karena itu keadaan perairan dikawasan ini menjadi keruh. Hal ini erat kaitannya dengan kekeruhan air yang disebabkan oleh lumpur, limbah rumah tangga 
dan limbah industri tahu relatif lebih tinggi sehingga cahaya yang masuk menjadi rendah.

c. $\mathrm{pH}$

Analisis korelasi $\mathrm{pH}$ dengan keanekaragaman udang menunjukan hasil koefisien korelasi $0,65 \mathrm{Hal}$ ini berarti adanya hubungan yang sedang atau cukup antara keduanya. Nilai koefisien determinasi yang diperoleh 42,2 \%. Artinya besarnya kontribusi $\mathrm{pH}$ terhadap keanekaragaman udang sebesar $42,2 \%$. Hal ini disebabkan oleh adanya penguraian dan peningkatan bahan-bahan organik yang mengandug unsur seperti nitrogen, oksigen, fosfor, halogen dan belerang yang dapat terurai yang menyebabkan tingginya nilai $\mathrm{pH}$.

d. COD

Analisis korelasi COD dengan keanekaragaman udang menunjukan hasil koefisien korelasi 0,835 . Hal ini berarti adanya hubungan yang kuat antara keduanya. Nilai koefisien determinasi yang diperoleh $69,7 \%$. Artinya besarnya kontribusi COD terhadap keanekaragaman udang sebesar 69,7\%. Dengan tingginya hubungan keanekaragaman udang dengan pengukuran COD berdampak pada rendahnya nilai indeks keanekragaman udang yang didapat pada setiap masing masing stasiun, yang mana bahan buangan pada sungai bederak berasal dari bahan buangan limbah rumah tangga, peternakan, industri rumah tangga yang menyebabkan sedikitnya sisa kandungan oksigen sehingga nilai COD menjadi menigkat.

\section{e. BOD}

Analisis korelasi BOD dengan keanekaragaman udang menunjukan hasil koefisien korelasi 0,98 . Hal ini berarti adanya hubungan yang sangat kuat antara keduanya. Nilai koefisien determinasi yang diperoleh 96 $\%$. Artinya besarnya kontribusi BOD terhadap keanekaragaman udang sebesar $96 \%$. Hasil pembuangan sisa limbah makanan maupun kotoran ternak merupakan bahan buangan organik yang dapat membusuk atau terdegradasi oleh mikroorganisme, sehingga hal ini akan menaikkan populasi mikroorganisme di perairan. Keadaan ini akan menyebabkan kebutuhan oksigen terlarut yang diperlukan oleh mikroorganisme dalam mengoksidasi bahan organik, dimana kadar BOD akan naik (Tatangindatu, 2013). f. $\mathrm{NO}_{3}$

Analisis korelasi $\mathrm{NO}_{3}$ dengan keanekaragaman udang menunjukan hasil koefisien korelasi 0,86. Hal ini berarti adanya hubungan yang kuat antara keduanya. Nilai koefisien determinasi yang diperoleh 73,9 \%. Artinya besarnya kontribusi $\mathrm{NO}_{3}$ terhadap keanekaragaman udang sebesar 73,9 \% yang mempengaruhi indeks keanekaragaman udang karena hasil pengujian sampel air yang diambil dari Sungai Bederak melebihi baku mutu kelas II. Nitrat $\left(\mathrm{NO}_{3}\right)$ bentuk utama nitrogen di perairan alami dan merupakan sumber nutrisi utama bagi pertumbuhan udang. Kadar nitrat yang lebih dari $5 \mathrm{mg} / \mathrm{L}$ menggambarkan telah terjadinya pencemaran pada perairan tersebut (Tatangindatu, 2013).

\section{Kesimpulan}

Kondisi sifat fisikokimia pada perairan Sungai Bederak pada parameter fisika seperti suhu belum melewati batas baku mutu kelas II, sedangkan tingkat kecerahan sudah tercemar dan menurut parameter kimia seperti pH sudah melewati batas baku mutu kelas II, COD belum melewati batas baku mutu kelas II, BOD sudah melewati batas baku mutu kelas II dan NO3 sudah melewati batas baku mutu kelas II yang ditetapkan pemerintahan.

Keanekaragaman udang yang didapat pada stasiun I 0,65, pada stasiun II 1,08, pada stasiun III 0,91, pada stasiun IV 1,59 dan pada stasiun $\mathrm{V}$ 1,86.

Ada hubungan antara suhu terhadap keanekaragaman udang sebesar 0,717, hubungan antara kekeruhan terhadap keanekaragaman udang sebesar 0,68, hubungan antara $\mathrm{pH}$ terhadap keanekaragaman udang sebesar 0,65, hubungan antara COD terhadap keanekaragaman udang sebesar 0,835, hubungan antara BOD terhadap keanekaragaman udang sebesar 0,98 dan hubungan antara $\mathrm{NO}_{3}$ terhadap keanekaragaman udang sebesar 0,86.

\section{Ucapan Terima Kasih}

Terima kasih kepada Ibu Dra. Meida Nugrahalia, M.Sc. selaku kepala laboratorium, dan Bapak Agus Wijaya selaku Laboran Laboratorium Biologi FMIPA Universitas 
Negeri Medan yang telah membantu selama proses penelitian.

\section{Daftar Pustaka}

Davie, P,J,F., (2002), Crustacea Malacostraca Phylocarida Eucarida Part 1, Zoological Catalogue, Australia.

Kanwilyanti, S., Suryanto, A., dan Supriharyono., (2013), Kelimpahan Larva Udang di Sekitar Perairan PT. Kayu Lapis Indonesia, Kaliwungu, Kendal, Vol. 2, No 4, Halaman 71-80.

Motoh, H., (1980), Field Guide For The Edible Crustacea of The Philippines, Aquaculture Department Iloilo, Philippines.

Nybakken, J. W., (1992), Biologi Laut. Suatu Pendekatan Ekologis, Alih Bahasa Oleh H. M. Eidman, PT. Gramedia, Jakarta.

Naamin, A., Farid, B., Sumiono, A., Suman., dan Subagyo, W., (1981), Potensi dan Penyebaran Sumber Daya Udang Ikan Laut di Perairan Indonesia, Direktorat Jendral Perikanan, Puslitbang Oceanologi LIPI.

Parlaungan, Y., (2015), Identifikasi Dan Pengelolaan Mutu Air Tambak Udang, Jakarta.

Peraturan Pemerintah Republik Indonesia No. 82 Tahun 2001. Tentang Pengelolaan Kualita Air dan pengendalian Pencemaran Air, Jakarta.

Rahmi., Annawaty., dan Fahri., (2016), Keanekaragaman Jenis Udang Air Tawar Di Sungai Tinombo Kecamatan Tinombo Kabupaten Parigi Moutong Provinsi Sulawesi Tengah, Lab. Biologi DasarJurusan Biologi Fakultas MIPA, UniversitasTadulako, Journal of Natural Science Vol 5(2).

Sastrawidjaya, A.T., (1991), Pencemaran Lingkungan, Rineka Cipta, Jakarta.

Steven., (2011), Hasil Perameter Kimia Analisis Nitrat (No3) Di Perairan Popsa, Fakultas Ilmu Kelautan Dan Perikanan Universitas Hasanuddin, Makasar.

Suparjo., M.N., (2008), Daya Dukung Lingkungan Perairan Tambak Desa Mororejo Kabupaten Kendal, Jurnal Saintek Perikanan, Vol. 4, No. 1.
Supriharyono., (2000), Pelestarian dan Pengelolaan Sumber Daya Alam di Wilayah Pesisir Tropis, PT. Gramedia, Jakarta.

Suyanto, S., Rachmatun dan Mudjiman, A., (1989), Budidaya Udang Windu. Cetakan ke-3, Penerbit Swadaya, Jakarta.

Tatangindatu, F., Kalesaran, O., Rompas, R., (2013), Studi Parameter Fisika Kimia Air pada Areal Budidaya Ikan di Danau Tondano Desa Paleloan, Kabupaten Minahasa, Budidaya Perairan, Vol. 1 No. 2. 